Check for updates

Cite this: RSC Adv., 2017, 7, 32185

Received 24th April 2017

Accepted 19th June 2017

DOI: $10.1039 / c 7 r a 04590$ e

rsc.li/rsc-advances

\section{Theoretical study on the photooxygenation and photorearrangement reactions of 3-hydroxyflavone $\uparrow$}

\author{
Zoltán Szakács, ${ }^{a}$ Mihály Kállay ${ }^{\mathrm{b}}$ and Miklós Kubinyi (DD *ac
}

The photooxygenation of 3-hydroxyflavone (3HF) into O-benzoyl salicylic acid and the photorearrangement of 3HF into 3-hydroxy-3-phenyl-indane-1,2-dione have been studied using theoretical calculations. These are the main photodegradation reactions of this versatile fluorescent probe which exhibits excited state intramolecular proton transfer (ESIPT). The Gibbs free energies for the ground/excited state species were computed at the DFT/TD-DFT level of theory. The calculations on the direct photooxygenation ( $\mathrm{T}_{1}$ state phototautomeric form of $3 \mathrm{HF}+{ }^{3} \mathrm{O}_{2}$ ) as well as on the photosensitized reaction $\left(\mathrm{S}_{0}\right.$ state normal form of $3 \mathrm{HF}+{ }^{1} \mathrm{O}_{2}$ ) confirmed the feasibility of the reaction routes via an endoperoxide intermediate. In contrast, the alternative mechanism, via an exoperoxide intermediate proved kinetically inaccessible. In the calculation of the rearrangement reaction, the $T_{1}$ state phototautomeric form was considered the reacting species (as indicated by photochemical experiments) and the free energy profile was calculated through $T_{1}$ stationary points. The results suggested the occurrence of an intermediate with a 1-indanone skeleton, formed through a transition state with a relatively high free energy barrier corresponding to the folding of the pyrone ring.

\section{Introduction}

3-Hydroxyflavone (3HF) is a dually fluorescent compound due to the excited state proton transfer (ESIPT, see Fig. 1) from its hydroxyl to its carbonyl group. The two emissive forms are

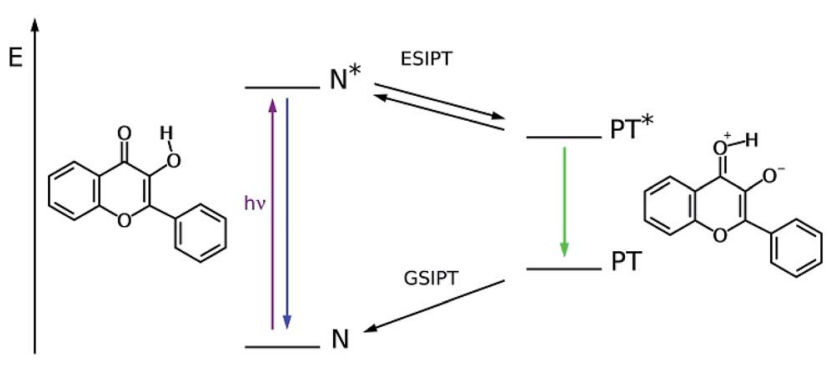

Fig. 1 The intramolecular proton transfer cycle of 3-hydroxyflavone.

\footnotetext{
${ }^{a}$ Department of Physical Chemistry and Materials Science, Budapest University of Technology and Economics, 1521 Budapest, Hungary.E-mail: kubinyi@mail.bme.hu ${ }^{b}$ MTA-BME Lendület Quantum Chemistry Research Group, Department of Physical Chemistry and Materials Science, Budapest University of Technology and Economics, 1521 Budapest, Hungary

'Institute of Materials and Environmental Chemistry, Research Center for Natural Sciences, Hungarian Academy of Sciences, 1519 Budapest, P.O. Box 286, Hungary

$\dagger$ Electronic supplementary information (ESI) available: Excitation energies of the normal and phototautomeric forms of 3-hydroxyflavone. Descartes coordinates of the stationary points in the three reactions. See DOI: $10.1039 / \mathrm{c} 7 \mathrm{ra04590e}$
}

usually referred to as the normal $\left(\mathrm{N}^{*}\right)$ and the phototautomeric $\left(\mathrm{PT}^{*}\right)$ species. Following the discovery of ESIPT in the $3 \mathrm{HF}$ parent compound by Sengupta and Kasha, ${ }^{\mathbf{1}}$ the phenomenon was studied in numerous natural and synthetic derivatives. ${ }^{2}$ The wavelength and intensity of the $\mathrm{N}^{*}$ and $\mathrm{PT}^{*}$ bands are sensitive to the local environment, which has led to the development of many $3 \mathrm{HF}$ based ratiometric fluorescent probes aimed at studying membrane structures, ${ }^{3,4}$ micellar assemblies, ${ }^{5-7}$ biomolecular interactions, ${ }^{8-10}$ and cellular processes ${ }^{11,12}$ and for use as chemosensors for the detection of non-fluorescent analytes. $^{\mathbf{1 3 , 1 4}}$ Much research effort has also been devoted to the construction of novel type ESIPT compounds, recent examples for which are the benzoindolizine derivative showing proton transfer from a protonated amino group to a ring C-atom, ${ }^{\mathbf{1 5 , 1 6}}$ and the amino-benzothiazols ${ }^{17,18}$ and amino-benzoquinolines ${ }^{19}$ with proton transfer along their (amino) $\mathrm{NH} \cdots \mathrm{N}$ (ring) hydrogen bonds.

In case of $3 \mathrm{HF}$ and some derivatives, the main photodegradation reactions have also been studied. The reaction routes proposed in the literature are summarized in Fig. 2. In the presence of dissolved oxygen, the direct photooxygenation was found to produce $O$-benzoyl salicylic acid (SA) and carbonmonoxide as the main photoproducts. ${ }^{20}$ The oxygenation of $3 \mathrm{HF}$ was also studied with the use of photosensitizers, and the same products (SA + CO) were obtained. ${ }^{21}$ The photooxygenation of some metal complexes with (anionic) 3HF ligand also yields SA, releasing CO. ${ }^{22-24}$ The direct as well as the photosensitized oxygenation of flavonols, the natural $3 \mathrm{HF}$ 

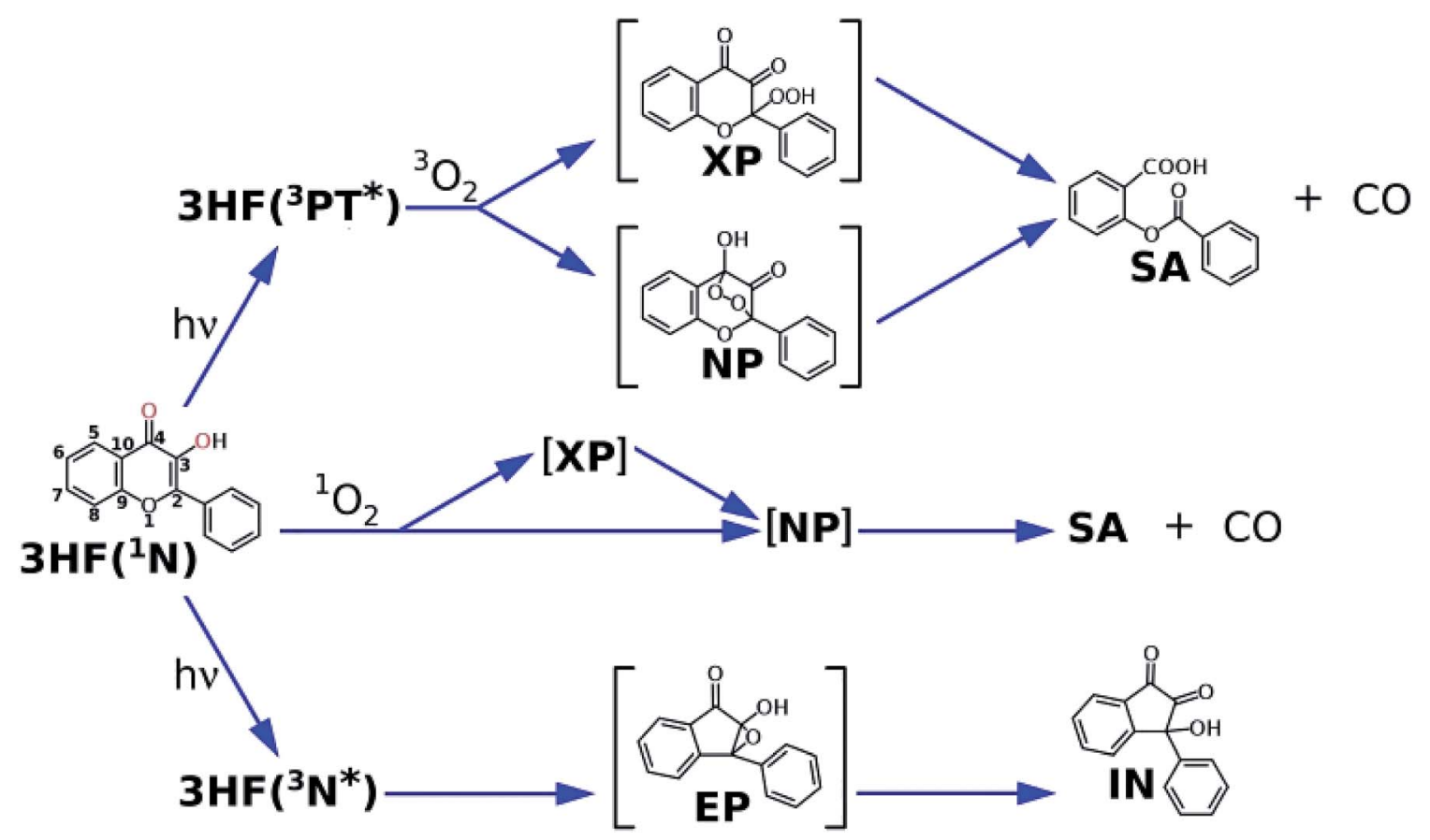

Fig. 2 Routes of photochemical reactions of 3HF, proposed in the literature; (top): unsensitized photooxygenation, (middle): sensitized photooxygenation, (bottom): photorearrangement.

derivatives, lead to the respective SA-s. ${ }^{25,26}$ In deaerated solutions, a photorearrangement takes place resulting in 3-hydroxy3-phenyl-indan-1,2-dione (IN). ${ }^{27}$ These reactions are of importance in the characterization of the photostability of 3HF-based fluorescent probes. ${ }^{28}$ In addition, there has been a particular interest for the photosensitized oxygenation of flavonols, as a process contributing to their antioxidant function in living organisms. ${ }^{29,30}$ Much information on the mechanism of these photoreactions has been collected via photolysis experiments.

The photooxygenation upon direct excitation of $3 \mathrm{HF}$ has been studied in air-saturated heptane ${ }^{20}$ and in low temperature $\mathrm{O}_{2}$ matrix $^{31}$ in detail. It was established that the triplet state tautomer is the reacting species and it forms a peroxide intermediate with ${ }^{3} \mathrm{O}_{2}$. In more detail, in apolar environments only the fluorescence of the $\mathrm{PT}^{*}$ form of $3 \mathrm{HF}$ could be observed, indicating that the ESIPT is a fast and complete reaction. This fluorescence was not sensitive to dissolved oxygen, i.e. the quenching of the $\mathrm{S}_{1}$ state tautomer was negligible. In contrast, the quenching of the $\mathrm{T}_{1}$ tautomeric form by ${ }^{3} \mathrm{O}_{2}$ had been detected in transient absorption experiments, and was explained in terms of physical quenching $\left(\mathrm{T}_{1}{ }^{-}{ }^{3} \mathrm{O}_{2}\right.$ energy transfer) and chemical reaction. This result is also in accord with the spin correlation rules, as the reactions of the two triplet species are spin-allowed, the singlet-triplet reactions are spinforbidden. The reaction proceeds via a concerted addition of $\mathrm{O}_{2}$ and a concomitant proton transfer, yielding the endoperoxide NP or the exoperoxide XP as primary product - the former was suggested by surface-enhanced Raman experiments, ${ }^{32}$ the latter by IR spectroscopic measurements in the $\mathrm{O}_{2}$ matrix. ${ }^{31}$ The peroxide NP or XP then decomposes into SA and carbonmonoxide.
The photosensitized oxygenation of 3HF occurs only in polar solvents (methanol, pyridine), the dye is inert to ${ }^{1} \mathrm{O}_{2}$ in apolar solvents. ${ }^{33}$ The reaction was interpreted by Matsuura ${ }^{21}$ in terms of the two-step mechanism seen in Fig. 2. ${ }^{1} \mathrm{O}_{2}$ binds to the $\mathrm{C}^{2}$ atom of $3 \mathrm{HF}$, yielding the exoperoxide intermediate, XP. This then transforms into the endoperoxide, NP, which decomposes thermally with the rupture of the peroxide bond and the splitting of a carbonmonoxide (involving the $\mathrm{C}^{3}$ and $\mathrm{O}^{3}(\mathrm{H})$ atoms in $3 \mathrm{HF}$ ). In another version of this mechanism suggested by Chou et al. ${ }^{33}$ the endoperoxide intermediate is formed directly from $3 \mathrm{HF}$, with an addition of ${ }^{1} \mathrm{O}_{2}$ to the $\mathrm{C}^{2}$ and $\mathrm{C}^{4}$ atoms of $3 \mathrm{HF}$ and a concomitant thermally activated proton transfer from the 3hydroxy to the 4-oxo group.

The photorearrangement is thought to start from the triplet state of the normal form of $3 \mathrm{HF}$ and goes through an epoxy intermediate, EP in Fig. 2. The triplet character of the reacting $3 \mathrm{HF}$ was indicated by quenching experiments: the triplet quenchers piperilene and isoprene inhibit the reaction. ${ }^{34}$ The occurrence of EP as an intermediate was proposed by Matsuura et al. ${ }^{27} \mathrm{EP}$ can be formed from the normal form of the flavone in a $(2+2)$ cycloaddition. As was pointed out by Chou et al. ${ }^{20}$ the vicinity of the proton on the 3-hydroxyl group to the epoxy oxygen is favorable for the conversion of EP into the diketonic final product. The cycloaddition of the phototautomer 3HF may lead to a tautomeric epoxy intermediate, with the proton on the 4-carbonyl group, remote from the epoxy oxygen atom, making the arrangement into the diketone unlikely. The reaction rate is increased in hydrogen bond donor solvents. ${ }^{35}$

Our target in the present work has been to calculate the potential energy surface (PES) theoretically, along the reaction 
paths of these photoreactions and to analyze the above mechanisms proposed on the bases of experimental results.

\section{Computational methods}

The quantum chemical calculations were performed using the Gaussian09 package of programs. ${ }^{36}$ The initial geometries of $3 \mathrm{HF}$ in its $\mathrm{N}$ and PT forms and the reaction products were computed with conformational analyses by MarvinSketch (version 16.4.25.0) using the MMFF94 force field. For each species the lowest-energy conformer was selected for further investigations. The M06-2X hybrid DFT functional ${ }^{37}$ with Pople's $6-311++\mathrm{G}^{* *}$ triple zeta basis set was employed for the geometry optimizations. The Gibbs free energies of the stationary points were computed in the rigid rotor harmonic oscillator approximation, using the same functional and basis set. The solvent effects were taken into account using the integral equation formalism polarizable continuum model (IEFPCM). ${ }^{38}$ The geometry optimizations of the ${ }^{1} \mathrm{~N}^{*}$ and ${ }^{1} \mathrm{PT}^{*}$ states of $3 \mathrm{HF}$ were started from the corresponding optimized ground state structures and computed at the TD-DFT level of theory.

The characterization of the first order saddle points (transition states, TS-s) were executed in two steps. First, the quadratic synchronous transit method (QST3) with the $6-31+\mathrm{G}^{*}$ basis set was employed, using either the optimized structures of the reactants and the products or a guess of the structures. Second, we optimized the TS-s using $6-311++\mathrm{G}^{* *}$ basis set, recomputing the Hessian in each cycle. The TS-s obtained this way were first order saddle points in each case. The initial structures of the intermediates (IM-s) were constructed from the prior transition states with minimal modifications. The stability of the selfconsistent field (SCF) solutions was checked in case of the singlet optimized structures. The unstable solutions were recalculated on the singlet surface by the unrestricted formalism, leading to spin contaminated states. The spin contamination was eliminated using Yamaguchi's method to calculate the corrected energies for the biradical structures. ${ }^{39,40}$

Basis set superposition errors were not estimated for the photooxygenation reaction because they are in the order of 1-2 kcal $\mathrm{mol}^{-1}$, which do not modify the hypothesized mechanisms.

The diradical character of the species, for which the SCF solutions were unstable, were described employing Complete Active Space SCF (CAS-SCF) calculations. ${ }^{41}$ The CAS-SCF wave functions were converged in three steps, using the STO-3G minimal basis set first, then the $6-31+G^{*}$, and finally the 6 $311++\mathrm{G}^{* *}$ basis set. The active space contained 4 electrons and 6 orbitals - CAS-SCF $(4,6)$ - in each case. Natural bond orbital (NBO) analyses were employed on the CAS-SCF wave functions to calculate the occupation numbers. Mulliken spin densities were calculated at the unrestricted $\mathrm{HF}(\mathrm{UHF}) / 6-311++\mathrm{G}^{* *}$ level on the singlet surface in the case of the unstable SCF solutions.

\section{Results and discussion}

The PES-s for the photorearrangement and unsensitized photooxygenation of $3 \mathrm{HF}$ were calculated in hexane solution, whereas the reaction route of the photsensitized oxygenation, which proceeds only in polar solvents, was calculated in acetonitrile. The Gibbs free energies of the ground state $\mathrm{N}$ form

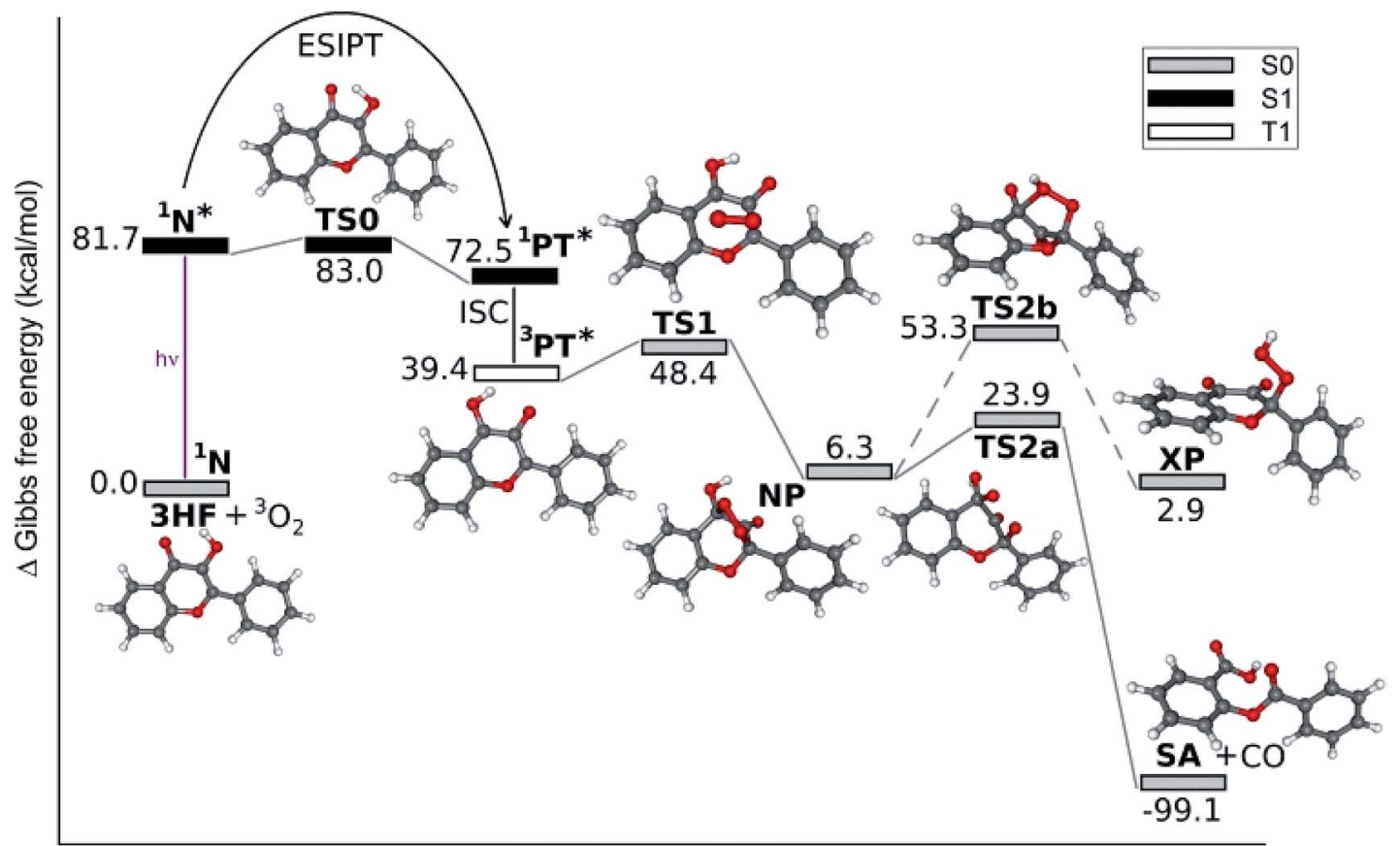

Reaction coordinate

Fig. 3 The calculated reaction path for the unsensitized photooxygenation of $3 \mathrm{HF}$. The triplet phototautomeric form of $3 \mathrm{HF}\left({ }^{3} \mathrm{PT} *\right)$ reacts with triplet oxygen. 
of $3 \mathrm{HF}$ (in all reactions), ${ }^{3} \mathrm{O}_{2}$ (in unsensitized oxygenation) and ${ }^{1} \mathrm{O}_{2}$ (in sensitized oxygenation) were taken to be zero. Energy corrections for spin contamination were necessary in cases of ${ }^{1} \mathrm{O}_{2}$ and of the transition states corresponding to the $3 \mathrm{HF}-\mathrm{O}_{2}$ adducts.

The route of the reaction of excited $3 \mathrm{HF}$ with ground-state oxygen is shown in Fig. 3. The initial step is the $S_{0} \rightarrow S_{1}$ excitation of the normal form of $3 \mathrm{HF}$, followed by the ESIPT process which proceeds via a low barrier transition state, TS0, producing the lower energy $S_{1}$ state phototautomeric form. We do not discuss the ESIPT of $3 \mathrm{HF}$ in more detail, as it has been the subject of thorough theoretical works. ${ }^{\mathbf{4 2} 45}$ The triplet tautomeric $3 \mathrm{HF},{ }^{3} \mathrm{PT}^{*}$, formed through an $\mathrm{S}_{1} \rightarrow \mathrm{T}_{n}$ inter-system crossing and subsequent internal conversion is the reactive species in the oxygenation with ${ }^{3} \mathrm{O}_{2}$. The excitation energies of the PT form were calculated using TD-DFT method and the $\mathrm{T}_{2}$ level was found close to $S_{1}$ (see Table $\mathrm{S} 1$ in ESI $\dagger$ ). The cyclic peroxide intermediate, NP, is formed via transition state TS1, which corresponds to a $3 \mathrm{HF}-\mathrm{O}_{2}$ pair, with the $\mathrm{O}_{2}$ oriented above the pyrone ring of the flavone at a distance of $\sim 2.6 \AA$. The final step is the dissociation of NP into the salicylic aldehyde, SA, and a carbon monoxide molecule, through the transition state TS2a, in which the peroxide bond strongly elongated, but the $\mathrm{C}^{2}=\mathrm{O}^{2}$ carbonyl unit has not split yet from the ring. The relatively low values of the Gibbs free energy barriers, $17.4 \mathrm{kcal}$ for the addition of triplet $\mathrm{O}_{2}$ on triplet $3 \mathrm{HF}$, and $17.6 \mathrm{kcal} \mathrm{mol}^{-1}$ for the dissociation of the endoperoxide, NP, clearly confirm the reasonability of this mechanism.

The alternative mechanism via the exohydroperoxide intermediate, XP, was found kinetically inaccessible (see dashed line route in Fig. 3). PES calculations for the addition of a ground state oxygen to the $\mathrm{T}_{1}$ state phototautomeric $3 \mathrm{HF}$, starting from various initial alignments of the reactants, always led to the endoperoxide intermediate, NP, as the first local minimum. In principle, NP might then isomerize into XP, with the rupture of the (peroxide) $\mathrm{O}-\mathrm{C}^{4}$ bond and a concomitant proton transfer from the $\mathrm{OH}$ group (dashed line in Fig. 3), but the high barrier $\left(47.0 \mathrm{kcal} \mathrm{mol}^{-1}\right)$ makes this process improbable as a thermal reaction.

The results describing the diradicaloid character of TS2a are illustrated in Fig. 4. The O-O distance stretched to $1.863 \AA$ from $1.456 \AA$ in the NP cyclic peroxide intermediate. The CAS-SCF (4, 6) calculations found three dominant configurations (with coefficients higher than \pm 0.1 ): the (110000), (100001) and (011000) configurations with coefficients of $0.925,-0.351$, and -0.135 , respectively (in the configuration notations the orbitals start from HOMO-1 and ' 1 ' denotes doubly occupied orbitals). As can be seen in Fig. 4, the bonding and antibonding orbitals of the splitting peroxide group and of the benzo ring participate in the dominant configurations. The diradicaloid nature (DR) was quantified as $\mathrm{DR}=[2-n(\mathrm{HOMO})] \times 100 \%$, where $n$ means the NBO occupation number. DR $=29 \%$ was obtained, indicating a weak diradicaloid character. ${ }^{46}$

The reaction path of the sensitized oxygenation of $3 \mathrm{HF}$ (ground state $\mathrm{N}$ form $+{ }^{1} \mathrm{O}_{2}$ ) is shown in Fig. 5. The addition of the $\mathrm{O}_{2}$ and the proton transfer between the $\mathrm{OH}$ and $\mathrm{CO}$ groups of the pyrone ring are concerted changes here. The energy

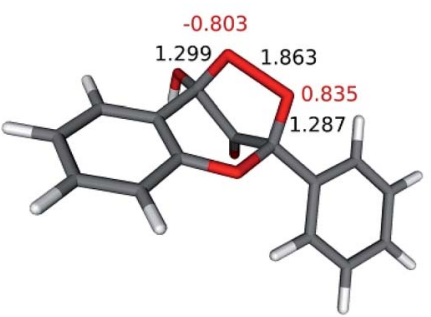

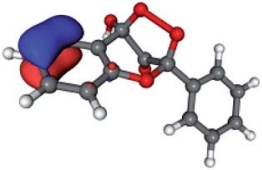

HOMO-1

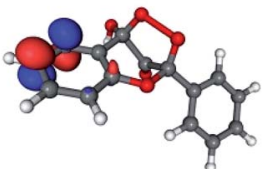

LUMO

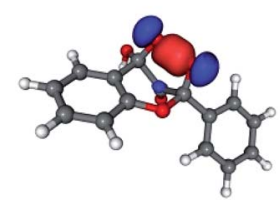

HOMO

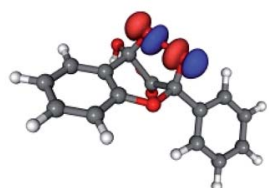

LUMO+3
Fig. 4 Structure of transition state TS2a in the oxygenation of $3 \mathrm{HF}$ with ${ }^{3} \mathrm{O}_{2}$. (Top) Bond lengths at the splitting peroxide bond (in black), UHF Mulliken spin densities on the $\mathrm{O}$ atoms (in red). (Below) MO-s contributing to the dominant configurations of the CAS-SCF wave function.

barrier towards the cyclic peroxide intermediate, NP, is higher only by $1 \mathrm{kcal} \mathrm{mol}^{-1}$ than in the direct photooxygenation. There are some structural differences between the TS1 transition states in the two reactions: the alignment of $\mathrm{O}_{2}$ over the flavone is different, the 2-phenyl ring is tilted with respect to the chromone unit. NP and TS2a, the further stationary points and the SA product are not identical, either, to the respective species in the unsensitized photooxygenation, because different solvents were considered in the two calculations.

The question if the addition of ${ }^{1} \mathrm{O}_{2}$ on an $\alpha, \beta$-unsaturated oxo compound results in an endoperoxide or an exoperoxide in the first step, has been studied on several examples. The formation of an exoperoxide becomes the dominant reaction if the oxo compound has a methyl group in the $\alpha$-position. The mechanism of this 'ene' reaction has been studied theoretically in detail in case of 2-methyl-2-butenal, ${ }^{47}$ but cyclic unsaturated ketones, like 2-methyl furanone also show ene reaction. ${ }^{48} 3 \mathrm{HF}$, with a $\mathrm{OH}$-group in the $\alpha$-position, hydrogen bonded to the carbonyl O-atom, seems unsuitable for such reaction. Our case is more similar to the oxidation of resveratrol. As the theoretical calculations by Sicilia et al. indicate, ${ }^{49}$ the cycloaddition of ${ }^{1} \mathrm{O}_{2}$ on the resorcine unit in resveratrol would be kinetically accessible, but the conversion of the endoperoxide formed into a hydroperoxide, with a proton transfer from a HO-group would be hindered by a high activation barrier.

The CAS-SCF calculations on TS2a in this reaction found that the (110000), (100001) and (010010) configurations were dominant with coefficients of $0.927,-0.348$ and -0.133 , respectively. The occupied MOs in the above configurations are shown in Fig. 6. For the diradicaloid parameter $\mathrm{DR}=30 \%$ was obtained. 


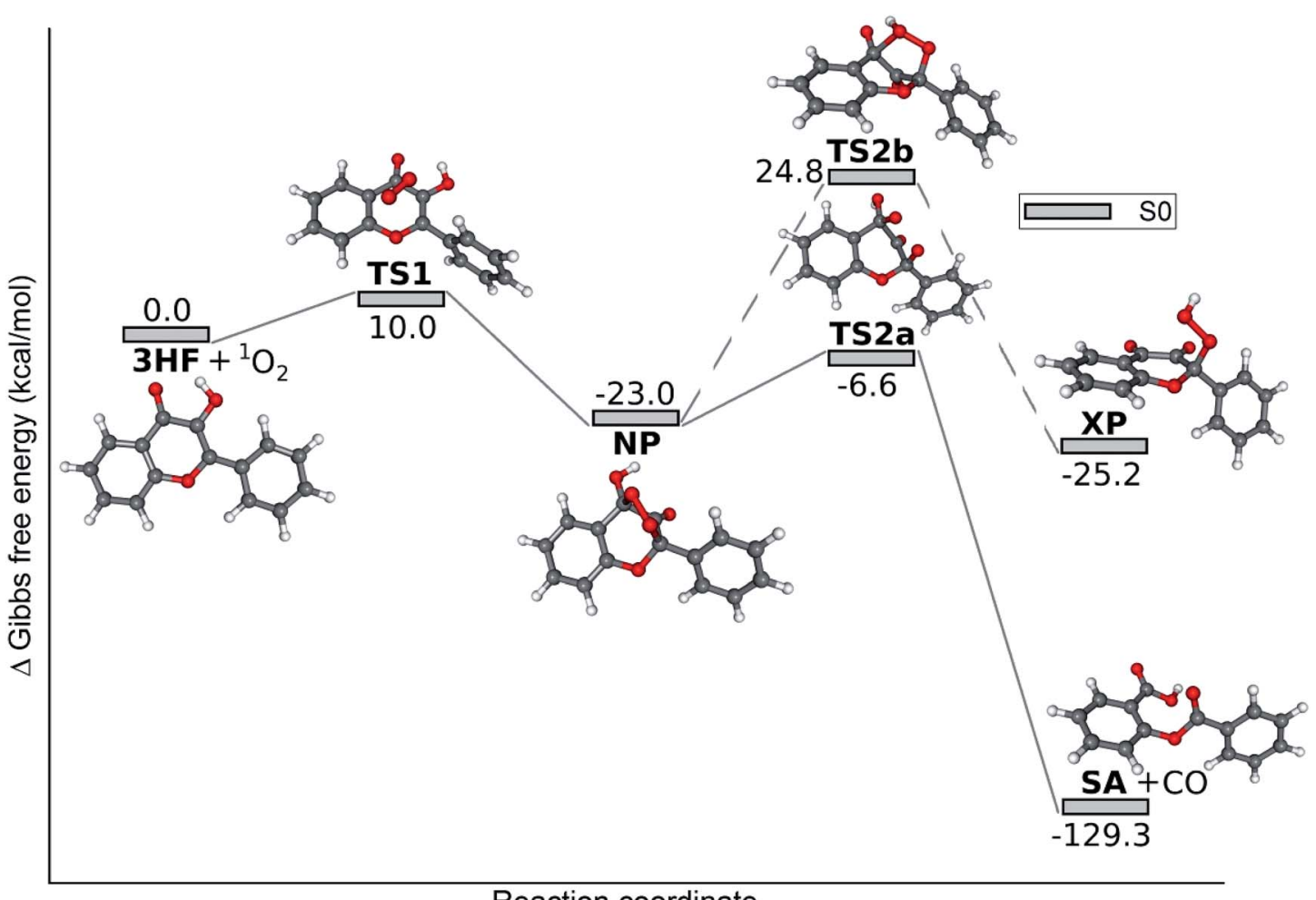

Fig. 5 Calculated reaction paths for the sensitized photooxygenation of $3 \mathrm{HF}$. The reactants are the $\mathrm{S}_{0}$ state $\mathrm{N}$ form of $3 \mathrm{HF}$ and singlet oxygen.

The reaction path for the photorearrangement of $3 \mathrm{HF}$ is displayed in Fig. 7. The $\mathrm{T}_{1}$ state normal form, ${ }^{3} \mathrm{~N}^{*}$, was considered the reacting species. The triplet state of the reactant is indicated by the observation that triplet quenchers block the

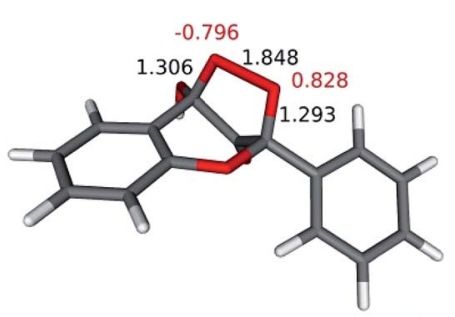

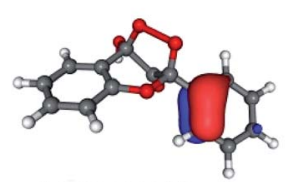

HOMO-1

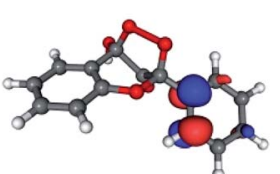

LUMO+2

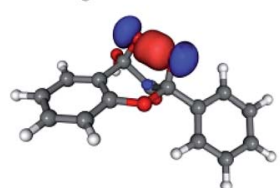

HOMO

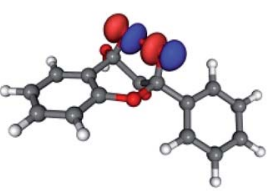

LUMO+3
Fig. 6 Structure of transition state TS2a in the photosensitized oxygenation of $3 \mathrm{HF}$. (Top) Bond lengths at the splitting peroxide bond (in black), UHF Mulliken spin densities on the $\mathrm{O}$ atoms (in red). (Below) $\mathrm{MO}-\mathrm{s}$ contributing to the dominant configurations of the CAS-SCF wave function. reaction. ${ }^{34}$ The $\mathrm{N}$ form was chosen as the reactant on the basis of the solvent effects described in the work of Protti and Mezzetti: ${ }^{35}$ the reaction took place only in polar solvents, whereas in apolar solvents, favoring for the ESIPT, no reaction occurred. The reaction was the fastest in protic polar solvents (alcohols), which - as hydrogen bond donors - block the ESIPT process.

The free energy profile was calculated through triplet stationary points, and the occurrence of an epoxy intermediate (EP in Fig. 2) was hypothesized initially. Instead, an intermediate with different structure, IM1 in Fig. 7, was found. Its formation is hindered by a relatively high free energy barrier (corresponding to the folding of the pyrone ring). This barrier may be noticeably lowered by specific solute-solvent interactions, not taken into account by the implicit solvation model (PCM) applied here. Furthermore, immediately following the intersystem crossing (ISC), the molecules have a large excess of energy. Considering the energies of the singlet and triplet levels of the $\mathrm{N}$ form of $3 \mathrm{HF}$ (Table $\mathrm{S} 1$ in ESI $\dagger$ ) the $\mathrm{S}_{1}$ state molecules are first converted into a high triplet state by ISC. Despite that the subsequent internal conversion and vibrational relaxation are ultrafast processes, ${ }^{\mathbf{5 0}}$ a fraction of the molecules may pass over the barrier at transition state TS1 before the relaxation is completed. In addition, the $\mathrm{S}_{0} \rightarrow \mathrm{S}_{2}$ excitation also falls in the wavelength range of the UV lamps used most frequently in photolysis studies, and from $\mathrm{S}_{2}$ the molecule can get directly to an even higher excited triplet via ISC.

The importance of highly excited vibrational states in a similar photorearrangement reaction was underlined in a study on the photolysis of $\alpha$-cyclohexandione in solution 


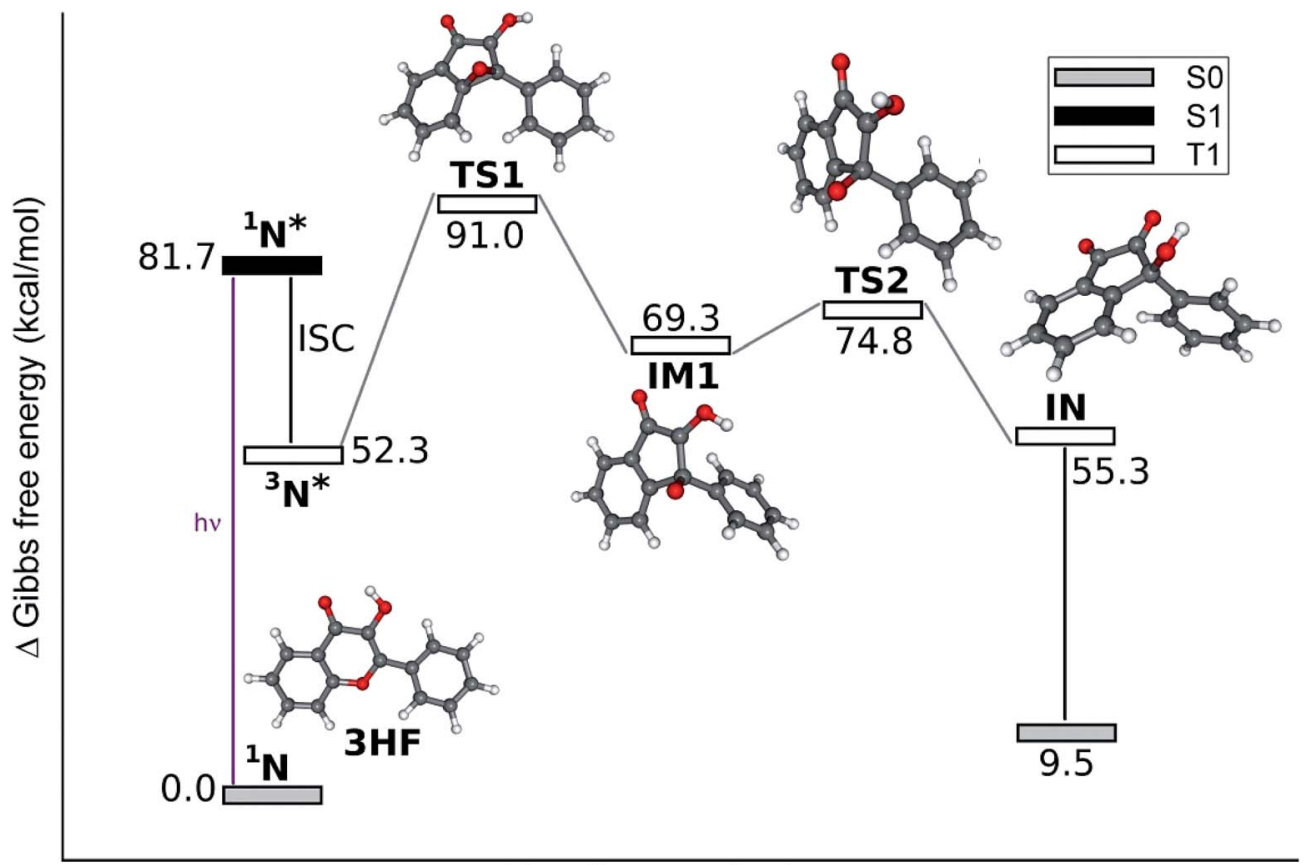

Reaction coordinate

Fig. 7 The reaction path of the photorearrangement of $3 \mathrm{HF}$ proceeding through triplet states.

phase. $^{51} \alpha$-Cyclohexandione occurs dominantly as an enol tautomer, thus it is structurally similar to the pyrone unit of $3 \mathrm{HF}$. It decomposes into furanone and $\mathrm{CO}$ as major products under UV irradiation. The theoretical calculations identified high activation barriers both on the $\mathrm{S}_{0}$ and $\mathrm{T}_{1}$ surfaces, indicating that the reaction can take place only from highly excited vibrational levels of the $S_{0}$ and $T_{1}$ state cyclohexandione molecules.

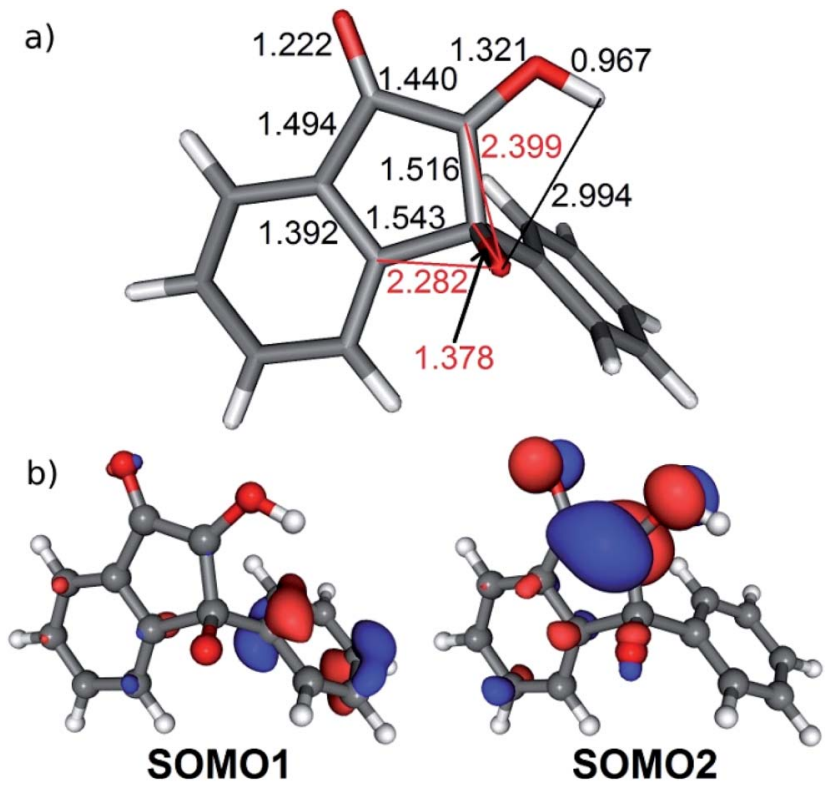

Fig. 8 (a) Selected bond lengths in the intermediate IM1 of the photorearrangement reaction. (b) Singly occupied molecular orbitals of IM1.
The calculated bond lengths in IM1, the next stationary point, are shown in Fig. 8a. They indicate (retaining the numbering of atoms in $3 \mathrm{HF}$ in Fig. 2) that the oxygen atom $\mathrm{O}^{1}$ is bound only to $\mathrm{C}^{2}\left[\mathrm{~d}\left(\mathrm{O}^{1}-\mathrm{C}^{2}\right)=1.378 \AA\right]$, the bond to the benzo ring, $\mathrm{O}^{1}-\mathrm{C}^{9}$ is ruptured, $\left[\mathrm{d}\left(\mathrm{O}^{1}-\mathrm{C}^{9}\right)=2.282 \AA\right]$, and a new bond to $\mathrm{C}^{3}$ is not created $\left[\mathrm{d}\left(\mathrm{O}^{1}-\mathrm{C}^{3}\right)=2.399 \AA\right]$. Consequently, IM1 can not be described as the epoxy intermediate (EP in Fig. 2) hypothesized in early experimental studies ${ }^{27}$ but is rather an 1indanone derivative. The two singly occupied molecular orbitals (SOMO-s) above the manifold of the fully occupied orbitals are displayed in Fig. 8b. As can be seen, the electron on SOMO1 is delocalized on the phenyl ring, whereas SOMO2 corresponds to a radical center on $\mathrm{C}^{3}$.

On the route towards TS2, the distance $\mathrm{O}^{1}-\mathrm{O}^{2}$ decreases due to the further torsion of the $\mathrm{OH}$ group. In TS2 this distance is only $2.25 \AA$, allowing a proton transfer to occur, leading to the indandione derivative product, IN.

We note that besides this triplet route, reaction routes involving a $\mathrm{T}_{1}-\mathrm{S}_{0}$ conical intersection are also possible, and they may pass through an epoxy intermediate, but these have not been studied at the present time.

\section{Conclusions}

The mechanisms of three photodegradation reactions of $3 \mathrm{HF}-$ its photooxygenation with ${ }^{3} \mathrm{O}_{2}$ into a salicylic acid SA derivative, its photosensitized oxygenation leading to the same product and its photorearrangement into an indanedione derivative, IN - have been investigated by computing the free energy profiles of the reactions. In the photooxygenation, ESIPT was taken as the initial step, which is practically complete in apolar solvents. 
As the calculations showed, the subsequent step, the addition of ${ }^{3} \mathrm{O}_{2}$ on the triplet state phototautomer, ${ }^{3} \mathrm{PT}^{*}$, is a cyloaddition, not an 'ene' reaction, i.e. the photooxygenation passes through a cyclic peroxide intermediate, EP, not a hydroperoxide intermediate, XP. The photosensitited oxygenation, when ${ }^{1} \mathrm{O}_{2}$ binds to ground state $\mathrm{N}$ form of $3 \mathrm{HF}$, is also a cycloaddition, which is concerted now with the proton transfer from the HO group to the $\mathrm{CO}$ group of the pyrone ring. For the photorearrangement, the PES was computed along the triplet states. The calculations suggested that the opening of the pyrone ring leads to an intermediate with 1-indanone skeleton which is then transformed by a direct proton transfer (without an epoxy intermediate supposed initially) into the IN final product. We hope that these theoretical results will be useful in the design of novel 3HF-based fluorescent probes.

\section{Acknowledgements}

This work was financially supported by the National Office for Research and Innovation (Grant K108752).

\section{Notes and references}

1 P. K. Sengupta and M. Kasha, Chem. Phys. Lett., 1979, 68, 382. 2 S. Protti and A. Mezzetti, in Specialist Periodical Report: Photochemistry, ed. A. Albani, Royal Society of Chemistry, Cambridge, 2012, vol. 40, p. 295.

3 A. S. Klymchenko, Y. Mely, A. P. Demchenko and G. Duportail, Biomembranes, 2004, 1665, 6.

4 V. Kilin, O. Glushonkov, L. Herdly, A. Klymchenko, L. Richert and Y. Mely, Biophys. J., 2015, 108, 2521.

5 S. Ghosh and N. Chattopadhyay, RSC Adv., 2015, 5, 49054.

6 D. Ghosh, S. Batuta, S. Das, N. A. Begumand and D. Mandal, J. Phys. Chem. B, 2015, 119, 5650.

7 D. Ghosh, S. Batuta, N. A. Begum and D. Mandal, J. Lumin., 2017, 184, 64.

8 O. M. Zamotaiev, V. Y. Postupalenko, V. V. Shvadchak, V. G. Pivovarenko, A. S. Klymchenko and Y. Mely, Bioconjugate Chem., 2011, 22, 101.

9 N. P. F. Barthes, I. A. Karpenko, D. Dziuba, M. Spadafora, J. Auffret, A. P. Demchenko, Y. Mely, R. Benhida, B. Y. Micheland and A. Burger, RSC Adv., 2015, 5, 33536.

10 M. Sholokh, O. M. Zamotaiev, R. Das, V. Y. Postupalenko,

L. Richert, D. Dujardin, O. A. Zaporozhets, V. G. Pivovarenko, A. S. Klymchenko and Y. Mely, J. Phys. Chem. B, 2015, 119, 2585.

11 V. V. Shynkar, A. S. Klymchenko, C. Kunzelmann, G. Duportail, C. D. Muller, A. P. Demchenko, J.-M. Freyssinet and Y. Mely, J. Am. Chem. Soc., 2007, 129, 2187.

12 Z. Darwich, O. A. Kucherak, R. Kreder, L. Richert, R. Vauchelles, Y. Mely and A. S. Klymchenko, Methods Appl. Fluoresc., 2013, 1, e025002.

13 F. Wang, J. S. Wu, X. Q. Zhuang, W. J. Zhang, W. M. Liu, P. F. Wang and S. K. Wu, Sens. Actuators, B, 2010, 146, 260.

14 M. Lan, J. Wu, W. Liu, H. Zhang, W. Zhang, X. Zhuang and P. Wang, Sens. Actuators, B, 2011, 156, 332.
15 V. K. Outlaw, J.-W. Zhou, A. E. Bragg and C. A. Townsend, RSC Adv., 2016, 6, 61249.

16 J.-W. Zhou, V. K. Outlaw, C. A. Townsend and A. E. Bragg, Chem.-Eur. J., 2016, 22, 15212.

17 H.-W. Tseng, J.-Q. Liu, Y.-A. Chen, C.-M. Chao, K.-M. Liu, C.-L. Chen, T.-C. Lin, C.-H. Hung, Y.-L. Chou, T.-C. Lin, T.-L. Wang and P.-T. Chou, J. Phys. Chem. Lett., 2015, 6, 1477. 18 C.-L. Chen, H.-W. Tseng, Y.-A. Chen, J.-Q. Liu, C.-M. Chao, K.-M. Liu, T.-C. Lin, C.-H. Hung, Y.-L. Chou, T.-C. Lin and P.-T. Chou, J. Phys. Chem. A, 2016, 120, 1020.

19 H.-W. Tseng, T.-C. Lin, C.-L. Chen, T.-C. Lin, Y.-A. Chen, J.-Q. Liu, C.-H. Hung, C.-M. Chao, K.-M. Liu and P.-T. Chou, Chem. Commun., 2015, 51, 16099.

20 W. E. Brewer, S. L. Studer, M. Standiford and P.-T. Chou, J. Phys. Chem., 1989, 93, 6088.

21 T. Matsuura, H. Matsushima and R. Nakashima, Tetrahedron, 1970, 26, 435.

22 S. Protti, A. Mezzetti, C. Lapougeand and J.-P. Cornard, Photochem. Photobiol. Sci., 2008, 7, 109.

23 K. Grubel, B. J. Laughlin, T. R. Maltais, R. C. Smith, A. M. Arif and L. M. Berreau, Chem. Commun., 2011, 47, 10431.

24 K. Grubel, S. L. Saraf, S. N. Anderson, B. J. Laughlin, R. C. Smith, A. M. Arif and L. M. Berreau, Inorg. Chim. Acta, 2013, 407, 91.

25 C. Tournaire, S. Croux, M. T. Maurette, I. Beck, M. Hocquaux, A. M. Braun and E. Oliveros, J. Photochem. Photobiol., B, 1993, 19, 205.

26 B. M. Fahlman and E. S. Krol, J. Photochem. Photobiol., B, 2009, 97, 123.

27 T. Matsuura, T. Takemoto and R. Nakashima, Tetrahedron, 1973, 29, 3337.

28 Z. Szakács, M. Bojtár, L. Drahos, D. Hessz, M. Kállay, T. Vidóczy, I. Bitter and M. Kubinyi, Photochem. Photobiol. Sci., 2016, 15, 219.

29 J. Morales, G. Günther, A. L. Zanocco and E. Lemp, PLoS One, 2012, 7, e0040548.

30 G. Günther, E. Berríos, N. Pizarro, K. Valdes, G. Montero, F. Arriagada and J. Morales, PLoS One, 2015, 10, e0129749.

31 P.-T. Chou, S. L. Studer, M. L. Martinez, E. Orton and M. Young, Photochem. Photobiol., 1991, 53, 581.

32 M. Wang, T. Spataru, J. R. Lombardi and R. L. Birke, J. Phys. Chem. C, 2007, 111, 3044.

33 S. L. Studer, W. E. Brewer, M. L. Martinez and P.-T. Chou, J. Am. Chem. Soc., 1989, 111, 7643.

34 I. Yokoe, K. Higuchi, Y. Shirataki and M. Komatsu, Chem. Pharm. Bull., 1981, 29, 894.

35 S. Protti and A. Mezzetti, J. Mol. Liq., 2015, 205, 110.

36 M. J. Frisch, G. W. Trucks, H. B. Schlegel, G. E. Scuseria, M. A. Robb, J. R. Cheeseman, G. Scalmani, V. Barone, B. Mennucci, G. A. Petersson, H. Nakatsuji, M. Caricato, X. Li, H. P. Hratchian, A. F. Izmaylov, J. Bloino, G. Zheng, J. L. Sonnenberg, M. Hada, M. Ehara, K. Toyota, R. Fukuda, J. Hasegawa, M. Ishida, T. Nakajima, Y. Honda, O. Kitao, H. Nakai, T. Vreven, J. A. Montgomery Jr, J. E. Peralta, F. Ogliaro, M. Bearpark, J. J. Heyd, E. Brothers, K. N. Kudin, V. N. Staroverov, R. Kobayashi, J. Normand, K. Raghavachari, A. Rendell, J. C. Burant, 
S. S. Iyengar, J. Tomasi, M. Cossi, N. Rega, J. M. Millam, M. Klene, J. E. Knox, J. B. Cross, V. Bakken, C. Adamo, J. Jaramillo, R. Gomperts, R. E. Stratmann, O. Yazyev, A. J. Austin, R. Cammi, C. Pomelli, J. W. Ochterski, R. L. Martin, K. Morokuma, V. G. Zakrzewski, G. A. Voth, P. Salvador, J. J. Dannenberg, S. Dapprich, A. D. Daniels, O. Farkas, J. B. Foresman, J. V. Ortiz, J. Cioslowski and D. J. Fox, Gaussian 09, Revision D.01, Gaussian, Inc., Wallingford, CT, 2009.

37 Y. Zhao and D. G. Truhlar, Theor. Chem. Acc., 2008, 120, 215.

38 J. Tomasi, B. Menucci and R. Cammi, Chem. Rev., 2005, 105, 2999.

39 S. Yamanaka, T. Kawakami, H. Nagao and K. Yamaguchi, Chem. Phys. Lett., 1994, 231, 25.

40 K. Yamaguchi, F. Jensen, A. Dorigo and K. N. Houk, Chem. Phys. Lett., 1988, 149, 537.

41 M. J. Frisch, I. N. Ragazos, M. A. Robb and H. B. Schlegel, Chem. Phys. Lett., 1992, 189, 524.

42 K. Tokumura, M. Kurauchi, N. Yagata and M. Itoh, Chem. Phys. Lett., 1996, 258, 495.
43 S. Ash, S. P. De, H. Beg and A. Misra, Mol. Simul., 2011, 37, 914.

44 M. A. Bellucci and D. F. Coker, J. Chem. Phys., 2012, 136, e194505.

45 A. Perveaux, M. Lorphelin, B. Lasorneb and D. Lauvergnat, Phys. Chem. Chem. Phys., 2017, 19, 6579.

46 C. S. Lopez, O. N. Faza, K. S. Feldman, M. R. Iyer and D. K. Hester, J. Am. Chem. Soc., 2007, 129, 7638.

47 A. Maranzana, C. Canepa, G. Ghigo and G. Tonachini, Eur. J. Org. Chem., 2005, 3643.

48 B.-M. Kwon, R. C. Kanner and C. S. Foote, Tetrahedron Lett., 1989, 30, 903.

49 G. Mazzone, M. E. Alberto, N. Russo and E. Sicilia, Phys. Chem. Chem. Phys., 2014, 16, 12773.

50 T. Kumpulainen, B. Lang, A. Rosspeintner and E. Vauthey, Chem. Rev., 2017, DOI: 10.1021/acs.chemrev.6b00491.

51 A. Mukhopadhyay, M. Mukherjee, A. K. Ghosh and T. Chakraborty, J. Phys. Chem. A, 2011, 115, 7494. 